\title{
Reliability Evaluation of NC Machine Tools considering Working Conditions
}

\author{
Hongzhou Li, ${ }^{1,2}$ Zhaojun Yang, ${ }^{1}$ Binbin Xu, ${ }^{1}$ Chuanhai Chen, \\ Yingnan Kan, ${ }^{1}$ and Guofei Liu ${ }^{1}$ \\ ${ }^{1}$ College of Mechanical Science and Engineering, Jilin University, Changchun 130025, China \\ ${ }^{2}$ College of Mechanical Engineering, Beihua University, Jilin 132013, China
}

Correspondence should be addressed to Binbin Xu; xubinbinjlu@foxmail.com

Received 16 November 2015; Accepted 17 February 2016

Academic Editor: Yuming Qin

Copyright (C) 2016 Hongzhou Li et al. This is an open access article distributed under the Creative Commons Attribution License, which permits unrestricted use, distribution, and reproduction in any medium, provided the original work is properly cited.

Reliability evaluation is the basis for reliability design of NC machine tools. Since traditional reliability evaluation methods do not consider the working conditions' effects on reliability, there is a great error of a result of a traditional method compared with an actual value. A new reliability evaluation model of NC machine tools is proposed based on the Cox proportional hazards model, which describes the mathematical relation between the working condition covariates and the reliability level of NC machine tools. Firstly, the coefficients of working condition covariates in the new reliability evaluation model are estimated by the partial likelihood estimation method; secondly, the working condition covariates which have no effects on the reliability of NC machine tools are eliminated by the likelihood ratio test; then parameters of the baseline failure rate function are estimated by the maximum likelihood estimation method. Thus, the reliability evaluation model of NC machine tool is obtained under different working conditions and the reliability level of NC machine tools is obtained. Case study shows that the proposed method could establish the relation between the working condition covariates and the reliability level of NC machine tools, and it would provide a new way for the reliability evaluation of NC machine tools.

\section{Introduction}

With the rapid development of high-speed and highprecision technologies, NC machine tools are becoming the main equipment for advanced manufacturing technology [1], and so they have been applied widely in many industries and regions. Kinds of machining workpieces are also very different from user to user. Meanwhile, the atmosphere pressure and temperature vary greatly from one region to another. Therefore, NC machine tools are usually in different working conditions [2]. Generally, different working conditions have different impacts on reliability of products [3], which have been confirmed by many researches [4-10]. Hu studied the influence of various road conditions on reliability of cars, and the strengthening coefficients based on the strengthening road conditions were obtained [4]. The reliability model of power system considering weather conditions was established and the weather conditions were divided into 3-state or 2 -state weather model $[5,6]$. In order to evaluate the reliability of electronic system, hybrid stochastic Petri net was used to establish the reliability model. And the reliability levels of the system under different temperature and voltage were obtained [7]. Chen et al. studied the failure physics equation, which is generalized Eyring model, of aerospace electrical connectors; the multiple-stress accelerated test scheme is adopted; then the reliability levels of aerospace electrical connectors under different temperature and vibration stresses were obtained [8]. Besides, some scholars established relations between the environmental stresses and reliability levels of some products by carrying out accelerated life tests $[11,12]$. Li et al. established the relationship between working conditions (the speed and load) and reliability of harmonic driver by accelerated life test [11]. Nogueira et al. studied temperature, humidity, and current impacts on reliability of high luminosity AlGaInP LEDs by accelerated life test [12]. Thus, it can be deduced from the above studies that working conditions would also affect the reliability of NC machine 
tools. Different working conditions cause different reliability levels, and the more different the working conditions are, the more obvious the disparity of the reliability levels is.

Reliability is one of the most important indicators of measuring the performance of $\mathrm{NC}$ machine tools, which has always been the researching focus by scholars [13-17]. Given that the result of reliability evaluation is influenced by many factors, methods including the Markov model [18], Petri net [19], Monto Carlo method [20], and Bayesian method [21] are applied to reliability evaluation of NC machine tools. However, for the present, the relation between reliability of the NC machine tools and the working conditions has not been established, which causes error in the result of reliability evaluation of NC machine tools compared with the actual value. Therefore, to decrease the evaluation error, it is of great engineering significance to establish the relation between the reliability of NC machine tools and the working conditions, which is also a hard problem in reliability research on NC machine tools.

In different research areas, there are many models to describe the relations between the reliability and the working conditions. Commonly seen models, besides [4-12], include Arrhenius Model [22], Inverse Power Law Model [23], and Cumulative Exposure Model [24], as well as other models [25]. However, each of them is usually aimed at a specific type of product. For the NC machine tool is a typical mechanicelectric-hydraulic system, the above methods are difficultly used to establish the relationship between working conditions and reliability.

The proportional hazards model is a life statistical model, which is usually used for survival analysis in medicine field $[26,27]$, and can describe relation between patients and influencing factor. Thus, a new reliability evaluation method for NC machine tools based on the Cox proportional hazards model is proposed in this paper. Working conditions of NC machine tools are taken as covariates, and then the relation between the reliability level of NC machine tools and the covariates is established based on the proposed model. The coefficients of working condition covariates of the proposed model are estimated by the partial likelihood method; the covariates which have no effects on the reliability of NC machine tools are eliminated by the likelihood ratio test; the parameters of baseline failure rate function are estimated by the maximum likelihood estimation. Then, the reliability model of NC machine tools is developed under different working conditions. A batch of NC machine tools is taken as the research object for case study, where the impact laws of environment temperature, cutting fluid, number of tool changes, and cutting force on the reliability of NC machine tools are researched, respectively. Finally, the feasibility of the proposed method is validated in the case study.

\section{Reliability Model of NC Machine Tools considering Working Conditions}

2.1. Proportional Hazards Model. The proportional hazards model was developed in 1972 by Cox, a British statistician.
This model considers the relation between failure rate and covariates, which is defined as [28]

$$
\lambda(t, \mathbf{X})=\lambda_{0}(t) g(\mathbf{X}),
$$

where $t$ is the time between failures (TBF, a random variable) of NC machine tools, $\mathbf{X}=\left(X_{1}, X_{2}, \ldots, X_{i}, \ldots, X_{n}\right)^{T}$ is the vector of working condition covariates, which affects the failure rate of NC machine tools, $X_{i}$ is the $i$ th covariate, such as cutting force, environment temperature, number of tool changes, or vibration, and $g(\mathbf{X})$ is function of working condition covariates.

In general, $g(\mathbf{X})$ can be expressed as

$$
g(\mathbf{X})=\exp (\boldsymbol{\beta} \mathbf{X})
$$

where $\boldsymbol{\beta}=\left(\beta_{1}, \beta_{2}, \ldots, \beta_{i}, \ldots, \beta_{n}\right)$ is the vector of $\mathbf{X}$ 's coefficients, which reflect the covariates' influences on the failure rate function, and $\beta_{i}$ is the coefficient of $X_{i}$. When $\beta_{i}>0$, it indicates that $X_{i}$ catalyzes the machine tools to fail; when $\beta_{i}=0, X_{i}$ has no effects on the failure rate of machine tools; when $\beta_{i}<0, X_{i}$ depresses the machine tools to fail. $\lambda_{0}(t)$ is the baseline failure rate of NC machine tools, that is, the failure rate function when $\mathbf{X}=0 ; \lambda(t, \mathbf{X})$ represents the failure rate function of NC machine tools under covariate $\mathbf{X}$.

Substituting (2) in (1) gets

$$
\lambda(t, \mathbf{X})=\lambda_{0}(t) \exp (\boldsymbol{\beta} \mathbf{X}) .
$$

Equation (3) is equivalent to the following equation:

$$
\frac{\lambda(t, \mathbf{X})}{\lambda_{0}(t)}=\exp (\boldsymbol{\beta} \mathbf{X}) \text {. }
$$

The failure rate function of NC machine tools under the covariate $\mathbf{X}_{1}$ is $\lambda\left(t, \mathbf{X}_{1}\right)$; thus,

$$
\frac{\lambda\left(t, \mathbf{X}_{1}\right)}{\lambda_{0}(t)}=\exp \left(\boldsymbol{\beta} \mathbf{X}_{1}\right) .
$$

According to (4) and (5), then

$$
\frac{\lambda(t, \mathbf{X})}{\lambda\left(t, \mathbf{X}_{1}\right)}=\exp \left[\boldsymbol{\beta}\left(\mathbf{X}-\mathbf{X}_{1}\right)\right] \text {. }
$$

Therefore,

$$
\lambda(t, \mathbf{X})=\lambda\left(t, \mathbf{X}_{1}\right) \exp \left[\boldsymbol{\beta}\left(\mathbf{X}-\mathbf{X}_{1}\right)\right] .
$$

Assume that the probability density function (PDF) of NC machine tools' TBF under covariate vector $\mathbf{X}$ is $f(t, \mathbf{X})$, and corresponding reliability function is $R(t, \mathbf{X})$. According to (7), $R(t, \mathbf{X})$ of NC machine tools is

$$
R(t, \mathbf{X})=R\left(t, \mathbf{X}_{1}\right)^{\exp \left[\boldsymbol{\beta}\left(\mathbf{X}-\mathbf{X}_{1}\right)\right]},
$$

where $R\left(t, \mathbf{X}_{1}\right)$ is the reliability function of NC machine tools under covariate vector $\mathbf{X}_{1}$.

$R\left(t, \mathbf{X}_{1}\right)$ can be expressed by

$$
R\left(t, \mathbf{X}_{1}\right)=\exp \left\{-\int_{-\infty}^{t} \lambda(t, u) d u\right\} .
$$


TBF of NC machine tools is generally considered to follow two-parameter Weibull distribution [2, 13, 21, 29, 30]. Suppose that, under working condition covariate $\mathbf{X}_{1}$, the failure rate function can be expressed by

$$
\lambda_{0}(t)=\frac{m}{\eta}\left(\frac{t}{\eta}\right)^{m-1}
$$

Therefore, (7) is equivalent to

$$
\lambda(t, \mathbf{X})=\frac{m}{\eta}\left(\frac{t}{\eta}\right)^{m-1} \cdot \exp \left[\boldsymbol{\beta}\left(\mathbf{X}-\mathbf{X}_{1}\right)\right]
$$

where $m$ is the shape parameter, $m>0 ; \eta$ is the scale parameter, $\eta>0$.

So

$$
R(t, \mathbf{X})=\left\{\exp \left[-\left(\frac{t}{\eta}\right)^{m}\right]\right\}^{\exp \left[\boldsymbol{\beta}\left(\mathbf{X}-\mathbf{X}_{1}\right)\right]} .
$$

Therefore, the PDF of NC machine tools' TBF considering the working conditions can be expressed as

$$
\begin{aligned}
f(t, \mathbf{X})= & \left\{\exp \left[-\left(\frac{t}{\eta}\right)^{m}\right]\right\}^{\exp \left[\boldsymbol{\beta}\left(\mathbf{X}-\mathbf{X}_{1}\right)\right]} \cdot \frac{m}{\eta}\left(\frac{t}{\eta}\right)^{m-1} \\
& \cdot \exp \left[\boldsymbol{\beta}\left(\mathbf{X}-\mathbf{X}_{1}\right)\right] .
\end{aligned}
$$

Then, MTBF of NC machine tools under covariate vector $\mathbf{X}_{1}$ can be obtained by

$$
\mathrm{MTBF}=\eta \Gamma\left(1+\frac{1}{m}\right),
$$

where $\Gamma(*)$ is Gamma function.

2.2. Parameter Estimation. There are several parameters and coefficients in (11), which are $m$ and $\eta$ and $\beta=$ $\left(\beta_{1}, \beta_{2}, \ldots, \beta_{i}, \ldots, \beta_{n}\right)$. Thus, a two-step estimation method to estimate these parameters and coefficients is employed. Firstly, $\boldsymbol{\beta}$ is estimated by the partial likelihood estimation method [31]; then, $m$ and $\eta$ are estimated by the maximum likelihood estimation method.

2.2.1. Covariate Coefficients Estimation. From (7), we can get

$$
\frac{\lambda(t, \mathbf{X})}{\lambda\left(t, \mathbf{X}_{1}\right)}=\exp \left[\boldsymbol{\beta}\left(\mathbf{X}-\mathbf{X}_{1}\right)\right]
$$

Assuming that there are $n$ failures, the $j$ th failure of $\mathrm{NC}$ machine tools can be expressed as $\left(t_{j}, \delta_{j}, \mathbf{X}_{j}\right)$, where $t_{j}$ is time between the $j-1$ th failure and the $j$ th failure; $\delta_{j}$ is an indicator variable of datum $t_{j}$; when $\delta_{j}=1, t_{j}$ is noncensoring time and when $\delta_{j}=0, t_{j}$ is censoring time.

Equation (16) is $k$ dimensional column vector, which indicates that there are $k$ covariates in the $j$ th failure of $\mathrm{NC}$ machine tools:

$$
\mathbf{X}_{j}=\left(X_{j 1}, X_{j 2}, \ldots, X_{j k}\right)^{T} .
$$

Therefore, the partial likelihood function is given by

$$
L(\boldsymbol{\beta})=\sum_{j=1}^{r} \frac{\exp \left(\mathbf{S}_{j} \boldsymbol{\beta}\right)}{\left(\sum_{l \in H\left(t_{j}\right)} \exp \left(\mathbf{X}_{l} \boldsymbol{\beta}\right)\right)^{d_{j}}},
$$

where $d_{j}$ is the number of failures whose TBF is equal to $t_{j}$. If $D_{j}$ is the set of failures of NC machine tools at time $t_{j}$, then $d_{j}=\left|D_{j}\right| . \mathbf{S}_{j}$ is the sum of working condition covariates of $d_{j}$ failures, and so $\mathbf{S}_{j}=\sum_{l \in D_{j}} \mathbf{X}_{l}$ when $l \in D_{j} ; H\left(t_{j}\right)$ is the set of data that NC machine tools do not fail and there is no censoring at $t_{j}$.

Now take the logarithm of both sides in (17); then

$$
\ln L(\boldsymbol{\beta})=\sum_{j=1}^{r} \mathbf{S}_{j} \boldsymbol{\beta}-\sum_{j=1}^{r} d_{j} \ln \left(\sum_{l \in H\left(t_{j}\right)} \exp \left(\mathbf{X}_{l} \boldsymbol{\beta}\right)\right) .
$$

Take the first derivative with respect to $\beta$ and let it be equal to zero, so

$$
\begin{array}{r}
\frac{\partial \ln L(\boldsymbol{\beta})}{\partial \beta_{p}}=\sum_{j=1}^{r}\left(S_{j p}-d_{j} \frac{\sum_{l \in H\left(t_{j}\right)} X_{l p} \exp \left(\mathbf{X}_{l} \boldsymbol{\beta}\right)}{\sum_{l \in H\left(t_{j}\right)} \exp \left(\mathbf{X}_{l} \boldsymbol{\beta}\right)}\right) \\
p=(1,2, \ldots, k),
\end{array}
$$

where $S_{j p}$ is the $p$ th element in $S_{j}=\left(S_{j 1}, S_{j 2}, \ldots, S_{j k}\right)$.

There is no analytical solution to (19). So NewtonRaphson iterative method is applied to estimating the parameters [32].

The second partial derivatives of $\ln L(\beta)$ consist of the $k \times k$ order matrix I, of which the elements are

$$
\begin{array}{r}
\mathbf{I}_{p q}(\boldsymbol{\beta})=\frac{\partial^{2} \ln L(\boldsymbol{\beta})}{\partial \beta_{p} \cdot \partial \beta_{q}}=\sum_{j=1}^{r} d_{j}\left[\frac{\sum_{l \in H\left(t_{j}\right)} X_{l p} X_{l q} \exp \left(\mathbf{X}_{l} \boldsymbol{\beta}\right)}{\sum_{l \in H\left(t_{j}\right)} \exp \left(\mathbf{X}_{l} \boldsymbol{\beta}\right)}\right. \\
\left.-\frac{\left(\sum_{l \in H\left(t_{j}\right)} X_{l p} \exp \left(\mathbf{X}_{l} \boldsymbol{\beta}\right)\right) \cdot\left(\sum_{l \in H\left(t_{j}\right)} X_{l q} \exp \left(\mathbf{X}_{l} \boldsymbol{\beta}\right)\right)}{\left(\sum_{l \in H\left(t_{j}\right)} \exp \left(\mathbf{X}_{l} \boldsymbol{\beta}\right)\right)^{2}}\right],
\end{array}
$$

where $p, q=1,2, \ldots, k$.

So $\boldsymbol{\beta}$ can be estimated by Newton-Raphson numerical algorithm.

2.2.2. Elimination of No Impacting Covariate. In order to eliminate the covariates which have little or no impact on the reliability of NC machine tools, the likelihood ratio test is used and the procedure is shown in Figure 1 [33].

The likelihood ratio statistics are constructed according to (13) and (17). Suppose that there are $k$ covariates in the model and $-2 \ln \left[L(\widehat{\boldsymbol{\beta}}) / L\left(\widehat{\beta}_{i}\right)\right]$ is approximate Chi-square distribution whose degree of freedom is $k-1 . L(\widehat{\boldsymbol{\beta}})$ is the partial likelihood function of the model which does not contain covariate coefficient $\beta_{i}$, and $L\left(\widehat{\beta}_{i}\right)$ is partial likelihood function of the model which includes covariate coefficient $\beta_{i}$. So

$$
\lambda^{2}(k-1)=-2 \ln \left[\frac{L(\widehat{\boldsymbol{\beta}})}{L\left(\widehat{\beta}_{i}\right)}\right] .
$$




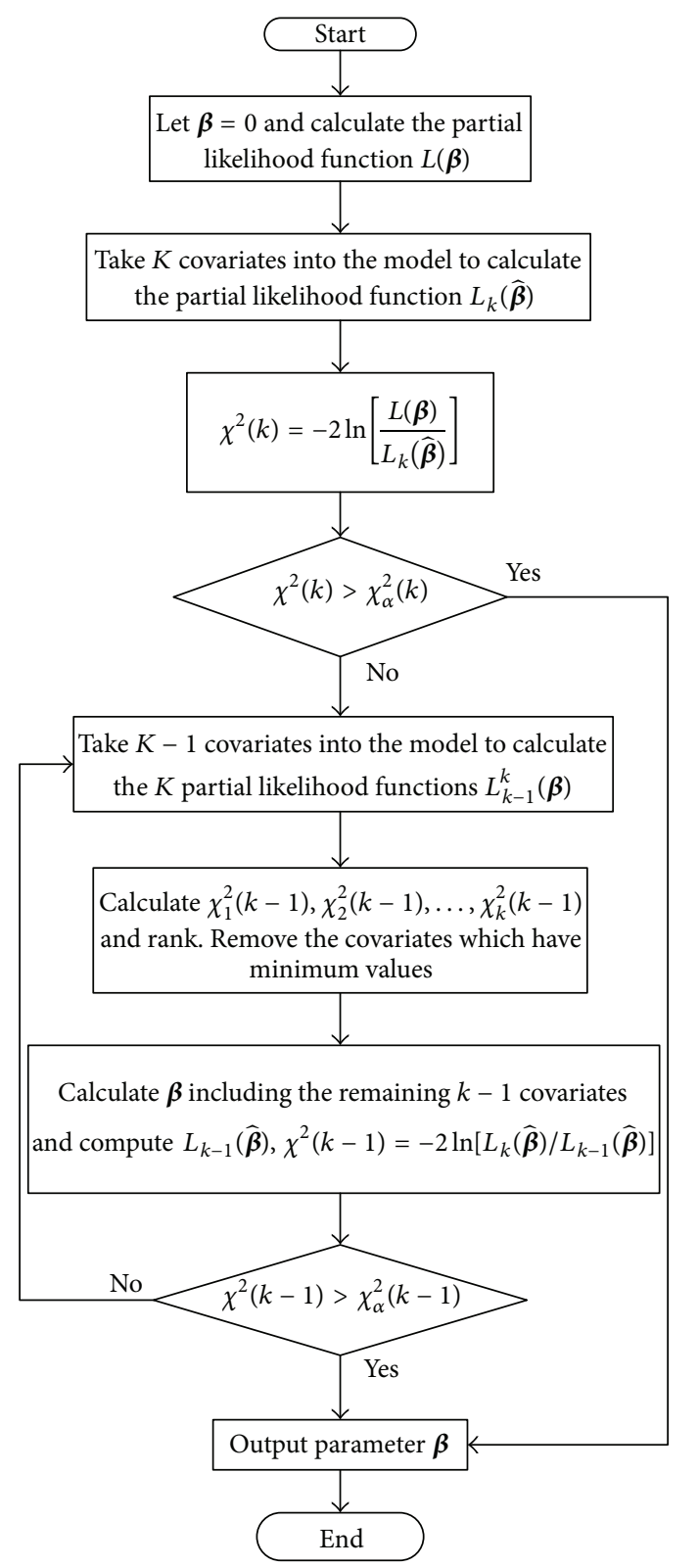

Figure 1: Procedure of the likelihood ratio test.

For a given confidence level $\alpha$, if $\lambda^{2}(k-1)>\lambda_{\alpha}^{2}(k-1)$, then $\beta_{i}$ has obvious effects on the model and it should be considered in the model; if $\lambda^{2}(k-1)<\lambda_{\alpha}^{2}(k-1)$, then $\beta_{i}$ has no effects on the model and it should not be considered.

\subsubsection{Parameters Estimation of Baseline Failure Function.}

The maximum likelihood estimation method is adopted to estimate the parameters $m$ and $\eta$ in (13), and the likelihood function is given as

$$
\begin{aligned}
& L(\eta, m)=\prod_{i=1}^{r} f\left(t_{i}, \mathbf{X}_{i}\right) \prod_{i=r+1}^{n} R\left(t_{i}, \mathbf{X}_{i}\right) \\
& =\prod_{i=1}^{r}\left\{\left\{\exp \left[-\left(\frac{t_{i}}{\eta}\right)^{m}\right]\right\}^{\exp \left[\boldsymbol{\beta}\left(\mathbf{X}_{i}-\mathbf{X}_{1}\right)\right]}\right.
\end{aligned}
$$

$$
\begin{aligned}
& \left.\cdot \frac{m}{\eta}\left(\frac{t_{i}}{\eta}\right)^{m-1} \cdot \exp \left[\boldsymbol{\beta}\left(\mathbf{X}_{i}-\mathbf{X}_{1}\right)\right]\right\} \\
& \cdot \prod_{i=r+1}^{n}\left\{\exp \left[-\left(\frac{t_{i}}{\eta}\right)^{m}\right]\right\}^{\exp \left[\boldsymbol{\beta}\left(\mathbf{X}_{i}-\mathbf{X}_{1}\right)\right]} .
\end{aligned}
$$

Take the logarithm of both sides in (22); then

$$
\begin{aligned}
\operatorname{Ln}[L(\eta, m)] & \\
= & r \ln m-r m \ln \eta+(m-1) \ln \left(t_{1} t_{2} \cdots t_{r}\right) \\
& -\left[\left(\frac{t_{1}}{\eta}\right)^{m}+\left(\frac{t_{2}}{\eta}\right)^{m}+\cdots+\left(\frac{t_{r}}{\eta}\right)^{m}\right] \\
& +\boldsymbol{\beta}\left(\mathbf{X}_{1}+\mathbf{X}_{2}+\cdots+\mathbf{X}_{r}-r \mathbf{X}_{1}\right) \\
& +\sum_{i=r+1}^{n}\left[-\left(\frac{t_{i}}{\eta}\right)^{m} \exp \left[\boldsymbol{\beta}\left(\mathbf{X}_{i}-\mathbf{X}_{1}\right)\right]\right] .
\end{aligned}
$$

Take the partial derivative of the parameters $\eta$ and $m$ in (23), respectively, and then

$$
\begin{aligned}
& \frac{\partial L n[L(\eta, m)]}{\partial \eta}=-\frac{r m}{\eta}+\left[m t_{1}^{m} \eta^{(-m-1)}+m t_{2}^{m} \eta^{(-m-1)}\right. \\
& \left.+\cdots+m t_{r}^{m} \eta^{(-m-1)}\right] \\
& +\sum_{i=r+1}^{n}\left[m t_{i}^{m} \eta^{(-m-1)} \exp \left[\boldsymbol{\beta}\left(\mathbf{X}_{i}-\mathbf{X}_{1}\right)\right]\right] \\
& \frac{\partial L n[L(\eta, m)]}{\partial m}=\frac{r}{m}-r \ln \eta+\ln \left(t_{1} t_{2} \cdots t_{r}\right) \\
& -\left[\left(\frac{t_{1}}{\eta}\right)^{m} \ln \frac{t_{1}}{\eta}+\left(\frac{t_{2}}{\eta}\right)^{m} \ln \frac{t_{2}}{\eta}+\cdots\right. \\
& \left.+\left(\frac{t_{r}}{\eta}\right)^{m} \ln \frac{t_{r}}{\eta}\right] \\
& +\sum_{i=r+1}^{n}\left[-\left(\frac{t_{i}}{\eta}\right)^{m} \ln \left(\frac{t_{i}}{\eta}\right) \exp \left[\boldsymbol{\beta}\left(\mathbf{X}_{i}-\mathbf{X}_{1}\right)\right]\right]
\end{aligned}
$$

Since (24) have no analytical solutions, Newton-Raphson numerical algorithm is used to estimate parameters $\eta$ and $m$.

\section{Case Study}

3.1. Field Test Data Collection. The failure data and the corresponding load data analyzed in this study were collected from 19 machining centers which were used in two user enterprises located in southwest of China. These machining centers were traced from February 10, 2014, to June 20, 2014. The failure data includes failure happening time and ending time, failure cause, failure position, failure phenomenon, and the repair information, all of which are recorded in Appendix A by 
testers. The load data, including manufacturing procedure, cutting parameters, material, cutting fluid, and environment temperature, are all recorded in Appendix B by testers.

According to the failure data and the corresponding load data recorded in Appendix A and B, TBFs and corresponding cutting force, environment temperature, cutting fluid condition, number of tool changes, and other working conditions of the traced machining centers are elicited and arranged. Cutting force, number of tool changes, environmental temperature, and cutting fluid are chosen as the working condition covariates considering the limitation of the testing conditions. The environmental temperature, cutting fluid, and the number of tool changes can be found in Appendix B directly. As for the field reliability test, it is impossible to install force sensors on machine tools, and thus cutting force cannot be measured by the force sensor directly. Therefore, the average cutting force is calculated by empirical formula (25) [34] in combination with the data recorded in Appendix B:

$$
F_{c}=\frac{C_{F} a_{p}^{x_{F}} f_{z}^{y_{F}} a_{e}^{u_{F}} Z}{d_{0}^{q_{F}} n^{w_{F}}}
$$

where $C_{F}, x_{F}, y_{F}, u_{F}, q_{F}$, and $w_{F}$ are coefficients which can be found in [34]; $a_{p}$ is the depth of cuts; $f_{z}$ is the feed of a tooth; $a_{e}$ is the cutting breadth; $z$ is the number of milling cutter teeth; $d_{0}$ is the diameter of milling cutter; $n$ is the rotation speed of milling cutter.

Machining centers used in the first enterprise are mainly for machining cylinder block, cylinder head, connecting plate, and the corresponding mould workpieces. The cutting times of cylinder block, cylinder head, and connecting plate account for 89 percent of the total cutting time. Generally, the machining process of workpiece consists of several operations or more; we calculate cutting forces of the above workpieces, respectively, by the parameters of the operation whose cutting time is the longest. And machining centers in the second enterprise are mainly for machining flywheel, flywheel housing, and cylinder. While the cutting time of these workpieces accounts for about 92 percent of the total cutting time, we also calculate cutting forces of the three workpieces, respectively, by the parameters of the operation whose cutting time is the longest. The parameters of the longest cutting time of the above workpieces are shown in Table 1.

The average cutting force for the seven workpieces is calculated according to Table 1 and (25). The covariates, TBFs, and other data are shown in Table 2.

\subsection{Model Establishment and Comparison between the Tradi-} tional Method and the New Method. The coefficient $\beta$ of the covariate in the proportional hazards model is calculated by the partial likelihood estimation method and the likelihood ratio test, where $\alpha=0.05$. The results are shown in Table 3 .

It is seen from Table 3 that $\lambda^{2}(k)$ is greater than $\lambda_{0.05}^{2}(k)$ in the third step and there are only two covariates in the model, cutting force and number of tool changes, in the third step. Thus, the working condition covariates of cutting fluid and temperature $\left(19^{\circ} \mathrm{C}-22^{\circ} \mathrm{C}\right)$ have no effects on the reliability of NC machine tools.

The failure rate function with the following working condition covariates, cutting force $F_{c}=0.35 \mathrm{KN}$ and number of tool changes $N_{h}=2$, is chosen as the baseline failure rate function in (15). Then $m=1.2121$ and $\eta=1156$ in (15) are estimated by the maximum likelihood estimation method. The reliability models under different covariates are obtained and shown in Table 4.

The proportional hazard models under different working condition covariates shown in Table 4 can be transformed into Weibull failure rate models, and then MTBF can be obtained by (14), as shown in Table 5 .

For comparison, reliability model parameters and MTBF of NC machine tools obtained by the traditional method [35], which does not consider the working condition covariates and is based on two-parameter Weibull distribution, are also shown in Table 5. The traditional method uses only two columns (TBF and data type) of data in Table 2 of the same batch of NC machine tools. The detailed procedure of calculation of the traditional method is given in [35], and the corresponding evaluation result is shown in the last row of Table 5 .

For an obvious comparison, the last column of Table 5 gives the MTBF comparison (MC), which is obtained by

$$
\mathrm{MC}=\frac{\mathrm{MTBF}_{\text {new }}}{\mathrm{MTBF}_{\text {trad }}},
$$

where $\mathrm{MTBF}_{\text {trad }}$ is the MTBF obtained by the traditional method; $\mathrm{MTBF}_{\text {new }}$ is the MTBF under different working condition covariates obtained by the new method.

From Table 5, it is seen that the traditional method gives $\mathrm{MTBF}_{\text {trad }}=585.0025 \mathrm{~h}$, and the $\mathrm{MTBF}_{\text {new }}$ given by the new method varies with different working conditions of $\mathrm{NC}$ machine tools. For example, firstly, when the cutting force $F_{c}=1.03 \mathrm{KN}$ and the number of tool changes $N_{h}=$ $14, \mathrm{MTBF}_{\text {new }}$ is $351.8384 \mathrm{~h}$, which is only 0.6014 times of $\mathrm{MTBF}_{\text {trad }}$. Secondly, the reliability level $\mathrm{MTBF}_{\text {new }}$ could reach $1084.6 \mathrm{~h}$ when the cutting force and the number of tool changes are getting smaller $\left(F_{c}=0.35 \mathrm{KN}\right.$ and $\left.N_{h}=2\right)$, which is 1.8540 times of $\mathrm{MTBF}_{\text {trad }}$. Thirdly, when $N_{h}=4$, and $F_{c}$ changes from $0.54 \mathrm{KN}$ to $0.81 \mathrm{KN}$, the values of $\mathrm{MTBF}_{\text {new }}$ change from $1.4298 * \mathrm{MTBF}_{\text {trad }}$ to $1.1086 * \mathrm{MTBF}_{\text {trad }}$. And when the cutting force $F_{c}=0.84 \mathrm{KN}$ and the number of tool changes $N_{h}=6, \mathrm{MTBF}_{\text {new }}$ is $581.4844 \mathrm{~h}$, which is 0.994 times of $\mathrm{MTBF}_{\text {trad }}$. From the above analysis it can be seen that $\mathrm{MTBF}_{\text {new }}$ obtained by the new method increases as the cutting force or the number of tool changes increases. Only under some particular working conditions does the $\mathrm{MTBF}_{\text {trad }}$ obtained by the traditional method equal $\mathrm{MTBF}_{\text {new }}$.

From Table 5, the PDFs and cumulative distribution functions (CDFs) of NC machine tools' TBF under different working condition covariates obtained by the new method are shown in Figures 2 and 3, respectively. Meanwhile, the PDF and CDF obtained by the traditional method are also shown in Figures 2 and 3.

It is seen from Figures 2 and 3 that there are obvious distinctions between the PDF curves and CDF curves obtained 


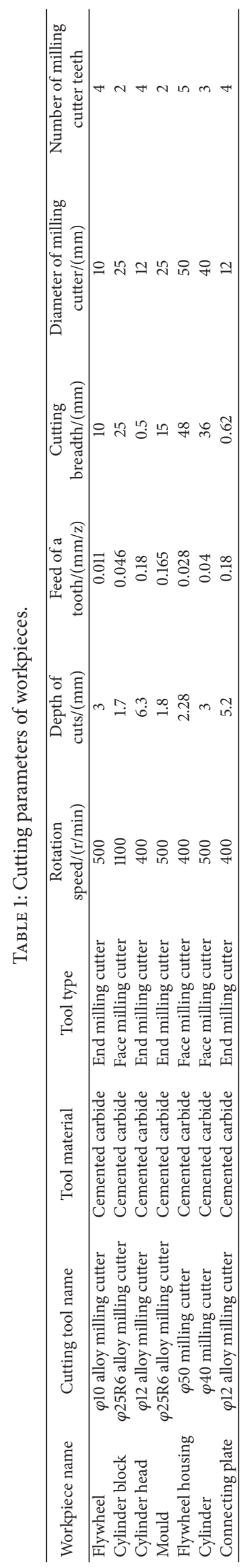


TABLE 2: Failure data of NC machine tools under different working conditions covariates.

\begin{tabular}{|c|c|c|c|c|c|c|}
\hline Workpiece name & Cutting force/KN & $\begin{array}{l}\text { Number of tool } \\
\text { changes/(N/h) }\end{array}$ & $\begin{array}{l}\text { Cutting } \\
\text { fluid }\end{array}$ & Temperature $/{ }^{\circ} \mathrm{C}$ & $\mathrm{TBF} / \mathrm{h}$ & $\begin{array}{l}\text { Data } \\
\text { type }\end{array}$ \\
\hline Flywheel & 0.35 & 2 & 1 & 20 & 437 & 1 \\
\hline Flywheel & 0.35 & 2 & 1 & 20 & 1896 & 1 \\
\hline Flywheel & 0.35 & 2 & 1 & 20 & 340 & 1 \\
\hline Flywheel & 0.35 & 2 & 1 & 20 & 244 & 1 \\
\hline Flywheel & 0.35 & 2 & 1 & 20 & 249 & 1 \\
\hline Flywheel & 0.35 & 2 & 1 & 20 & 898 & 1 \\
\hline Flywheel & 0.35 & 2 & 1 & 20 & 1148 & 0 \\
\hline Cylinder block & 0.43 & 17 & 0 & 21 & 158 & 1 \\
\hline Cylinder block & 0.43 & 17 & 0 & 21 & 67 & 1 \\
\hline Cylinder block & 0.43 & 17 & 0 & 21 & 242 & 1 \\
\hline Cylinder block & 0.43 & 17 & 0 & 21 & 107 & 1 \\
\hline Cylinder block & 0.43 & 17 & 0 & 21 & 155 & 1 \\
\hline Cylinder block & 0.43 & 17 & 0 & 21 & 1717 & 1 \\
\hline Cylinder block & 0.43 & 17 & 0 & 21 & 812 & 1 \\
\hline Cylinder block & 0.43 & 17 & 0 & 21 & 724 & 1 \\
\hline Cylinder head & 0.54 & 4 & 0 & 22 & 316 & 1 \\
\hline Cylinder head & 0.54 & 4 & 0 & 22 & 99 & 1 \\
\hline Cylinder head & 0.54 & 4 & 0 & 22 & 1419 & 1 \\
\hline Cylinder head & 0.54 & 4 & 0 & 22 & 1430 & 1 \\
\hline Cylinder head & 0.54 & 4 & 0 & 22 & 225 & 1 \\
\hline Cylinder head & 0.54 & 4 & 0 & 22 & 773 & 1 \\
\hline Cylinder head & 0.54 & 4 & 0 & 22 & 843 & 0 \\
\hline Mould & 0.78 & 10 & 1 & 19 & 398 & 1 \\
\hline Mould & 0.78 & 10 & 1 & 19 & 29 & 1 \\
\hline Mould & 0.78 & 10 & 1 & 19 & 401 & 1 \\
\hline Mould & 0.78 & 10 & 1 & 19 & 1148 & 1 \\
\hline Mould & 0.78 & 10 & 1 & 19 & 1012 & 1 \\
\hline Mould & 0.78 & 10 & 1 & 19 & 733 & 1 \\
\hline Mould & 0.78 & 10 & 1 & 19 & 1717 & 1 \\
\hline Mould & 0.78 & 10 & 1 & 19 & 773 & 1 \\
\hline Mould & 0.78 & 10 & 1 & 19 & 445 & 0 \\
\hline Flywheel housing & 0.81 & 4 & 1 & 20 & 348 & 1 \\
\hline Flywheel housing & 0.81 & 4 & 1 & 20 & 167 & 1 \\
\hline Flywheel housing & 0.81 & 4 & 1 & 20 & 1232 & 1 \\
\hline Flywheel housing & 0.81 & 4 & 1 & 20 & 1118 & 1 \\
\hline Flywheel housing & 0.81 & 4 & 1 & 20 & 633 & 1 \\
\hline Flywheel housing & 0.81 & 4 & 1 & 20 & 382 & 1 \\
\hline Flywheel housing & 0.81 & 4 & 1 & 20 & 321 & 1 \\
\hline Flywheel housing & 0.81 & 4 & 1 & 20 & 576 & 0 \\
\hline Cylinder & 0.84 & 6 & 0 & 19 & 58 & 1 \\
\hline Cylinder & 0.84 & 6 & 0 & 19 & 37 & 1 \\
\hline Cylinder & 0.84 & 6 & 0 & 19 & 58 & 1 \\
\hline Cylinder & 0.84 & 6 & 0 & 19 & 592 & 1 \\
\hline Cylinder & 0.84 & 6 & 0 & 19 & 1008 & 1 \\
\hline Cylinder & 0.84 & 6 & 0 & 19 & 365 & 1 \\
\hline Cylinder & 0.84 & 6 & 0 & 20 & 1144 & 1 \\
\hline
\end{tabular}


TABLe 2: Continued.

\begin{tabular}{|c|c|c|c|c|c|c|}
\hline Workpiece name & Cutting force/KN & $\begin{array}{l}\text { Number of tool } \\
\text { changes } /(\mathrm{N} / \mathrm{h})\end{array}$ & $\begin{array}{l}\text { Cutting } \\
\text { fluid }\end{array}$ & Temperature $/{ }^{\circ} \mathrm{C}$ & $\mathrm{TBF} / \mathrm{h}$ & $\begin{array}{l}\text { Data } \\
\text { type }\end{array}$ \\
\hline Cylinder & 0.84 & 6 & 0 & 20 & 1430 & 1 \\
\hline Cylinder & 0.84 & 6 & 0 & 20 & 373 & 1 \\
\hline Cylinder & 0.84 & 6 & 0 & 20 & 659 & 1 \\
\hline Connecting plate & 1.03 & 14 & 1 & 22 & 234 & 1 \\
\hline Connecting plate & 1.03 & 14 & 1 & 22 & 175 & 1 \\
\hline Connecting plate & 1.03 & 14 & 1 & 22 & 190 & 1 \\
\hline Connecting plate & 1.03 & 14 & 1 & 22 & 151 & 1 \\
\hline Connecting plate & 1.03 & 14 & 1 & 22 & 18 & 1 \\
\hline Connecting plate & 1.03 & 14 & 1 & 22 & 530 & 1 \\
\hline Connecting plate & 1.03 & 14 & 1 & 22 & 349 & 1 \\
\hline Connecting plate & 1.03 & 14 & 1 & 22 & 526 & 1 \\
\hline Connecting plate & 1.03 & 14 & 1 & 22 & 368 & 1 \\
\hline Connecting plate & 1.03 & 14 & 1 & 22 & 174 & 1 \\
\hline
\end{tabular}

TABLE 3: Computation by the partial likelihood estimation method and the likelihood ratio test.

\begin{tabular}{|c|c|c|c|c|c|c|c|}
\hline \multirow{2}{*}{ Step } & \multirow{2}{*}{$k$} & \multicolumn{4}{|c|}{ Working conditions covariates } & \multirow{2}{*}{$\lambda^{2}(k)$} & \multirow{2}{*}{$\lambda_{0.05}^{2}(k)$} \\
\hline & & $\beta_{1}$ & $\beta_{2}$ & $\beta_{3}$ & $\beta_{4}$ & & \\
\hline 1 & 4 & 1.285 & 0.040 & -0.065 & 0.1340 & 7.871 & 9.488 \\
\hline 2 & 3 & 1.226 & 0.040 & & 0.1410 & 7.809 & 7.815 \\
\hline 3 & 2 & 1.142 & 0.049 & & & 6.552 & 5.991 \\
\hline
\end{tabular}

TABLE 4: Reliability models of NC machine tools under different working condition covariates.

\begin{tabular}{lcc}
\hline & Working condition covariates & Proportional hazards function $\lambda(t / X)$ \\
\hline$F_{c} / \mathrm{KN}$ & $N_{h} /(\mathrm{n} / \mathrm{h})$ & $\frac{1.2121}{1156}\left(\frac{t}{1156}\right)^{0.2121}$ \\
0.35 & 2 & $\frac{t}{0.2121} \cdot \exp [1.142 * 0.08+0.049 * 15]$ \\
0.43 & 17 & $\frac{1.2121}{1156}\left(\frac{1156}{1156}\right)$ \\
0.54 & 4 & $\frac{1.2121}{1156}\left(\frac{t}{1156}\right)^{0.2121} \cdot \exp [1.142 * 0.19+0.049 * 2]$ \\
0.78 & 10 & $\frac{1.2121}{1156}\left(\frac{t}{1156}\right)^{0.2121} \cdot \exp [1.142 * 0.43+0.049 * 8]$ \\
0.84 & 4 & $\frac{1.2121}{1156}\left(\frac{t}{1156}\right)^{0.2121} \cdot \exp [1.142 * 0.46+0.049 * 2]$ \\
1.03 & 6 & $\frac{1.2121}{1156}\left(\frac{t}{1156}\right)^{0.2121} \cdot \exp [1.142 * 0.49+0.049 * 4]$ \\
\hline
\end{tabular}

by the traditional method and the new methods. The PDF curve and the CDF curve obtained by the traditional method are only one single curve, and only under some particular working conditions are they close to the PDF curves and CDF curves obtained by the new method. When the values of cutting force or the number of tool changes are comparatively large (e.g., the cutting force $F_{c}=1.03 \mathrm{KN}$ and the number of tool changes $N_{h}=14$ ), the PDF curves and the CDF curves are steep. And when the values of cutting force or the number of tool changes are comparatively small (e.g., $F_{c}=0.35 \mathrm{KN}$ and $N_{h}=2$ ), the PDF curves and the CDF curves are even. It can be concluded from the above facts that, under different working conditions, the failure rate of NC machine tools is different, and the traditional method does not consider the differences in the results of reliability evaluation caused by different working conditions. 
TABLE 5: Comparison between the traditional method and the new method.

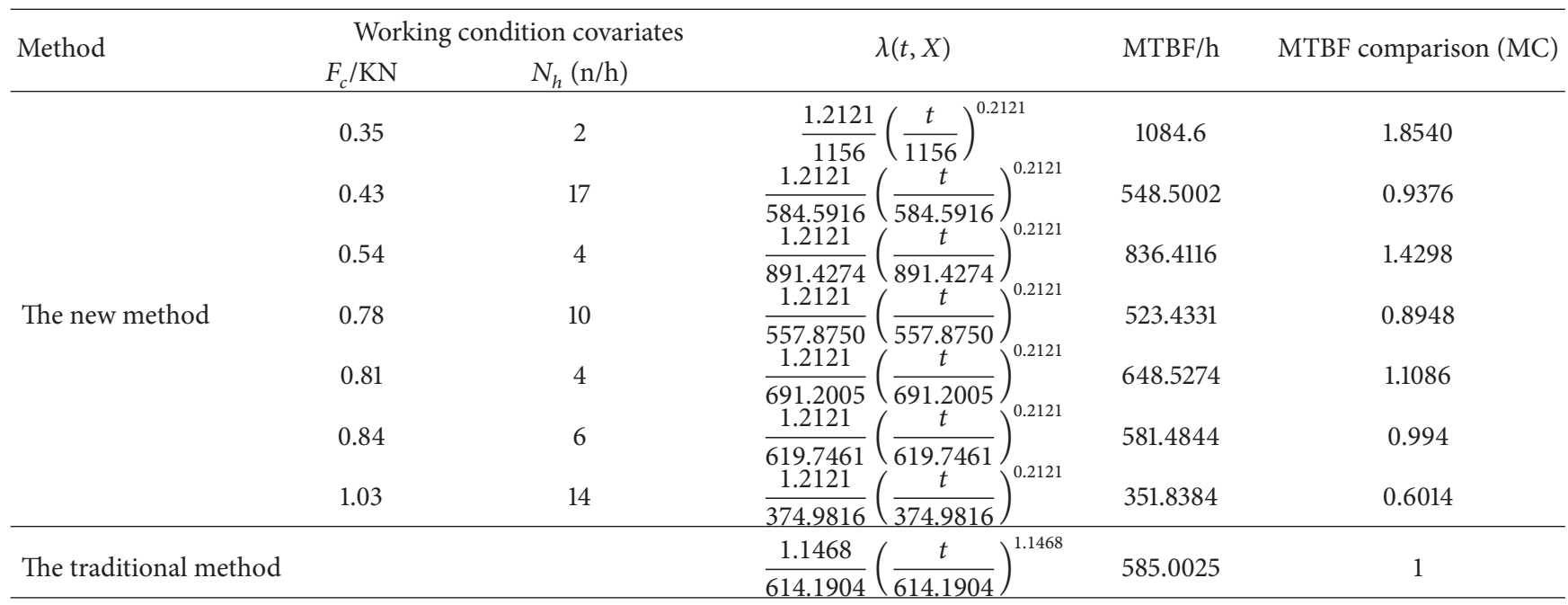

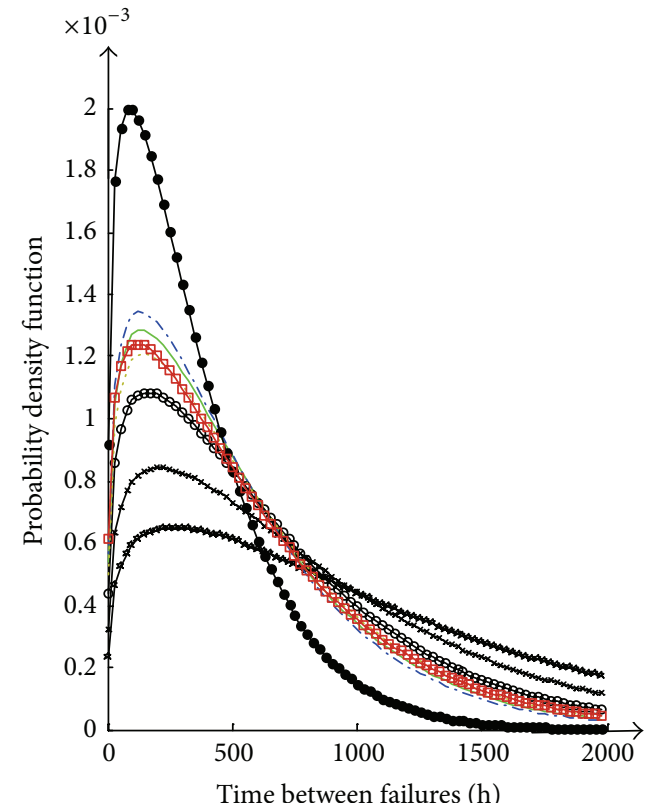

$$
\begin{aligned}
& \rightarrow F_{c}=0.35, N_{h}=2 \quad \rightarrow F_{c}=0.81, N_{h}=4 \\
& -F_{c}=0.43, N_{h}=17 \quad \ldots . . F_{c}=0.84, N_{h}=6 \\
& \longrightarrow F_{c}=0.54, N_{h}=4 \longrightarrow F_{c}=1.03, N_{h}=14 \\
& \text {... } F_{c}=0.78, N_{h}=10 \quad \square \text { Traditional method }
\end{aligned}
$$

Figure 2: PDFs obtained by the new method and the traditional method, respectively.

Therefore, the working conditions must be considered in evaluating the reliability level of NC machine tools.

\section{Conclusions}

The same NC machine tools under different working conditions have different reliability level. However, traditional reliability evaluation methods do not consider the impacts of working conditions on the reliability of NC machine

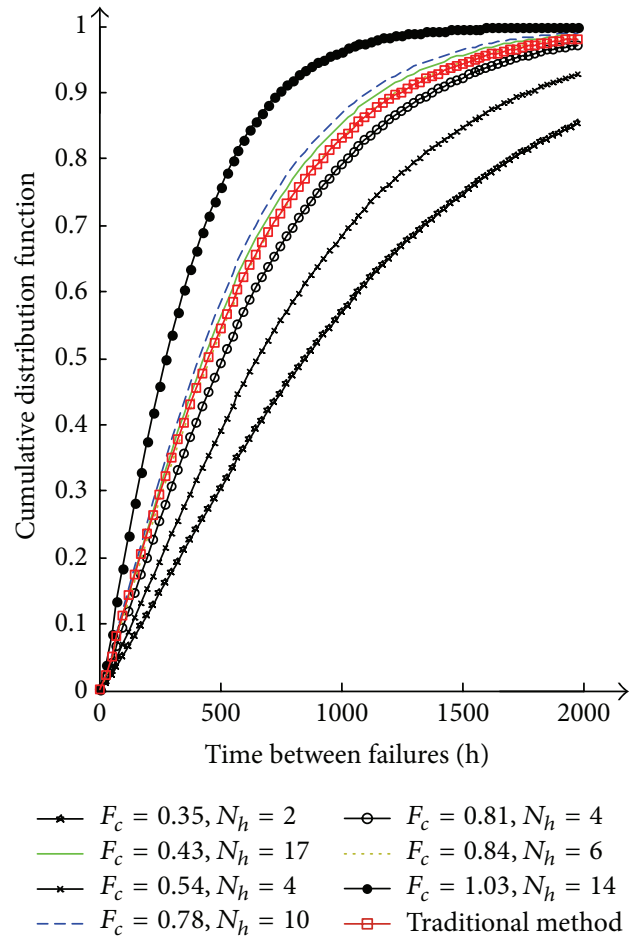

FIGURE 3: CDFs obtained by the new method and the traditional method, respectively.

tools. Considering this problem, the authors propose a new method for NC machine tools' reliability evaluating. The Cox proportional hazards model is used to establish the mathematical relation model between the NC machine tools' reliability and the corresponding working conditions. The likelihood ratio test is used to eliminate the working condition covariates which have no effects on the reliability of $\mathrm{NC}$ machine tools. In the parameter estimating process, a twostep estimation method is applied. That is, the coefficients of working condition covariates are firstly estimated by the 
partial likelihood estimation method, and then the maximum likelihood estimation method is used to estimate the parameters of the baseline failure rate function. Finally, a practical application case is presented. The new method is used for evaluating reliability of NC machine tools under different working conditions, which have 4 covariates (the cutting force, the number of tool changes, the cutting fluid, and the environment temperature). By the likelihood ratio test, the cutting fluid and the environment temperature (within the range of 19 22 degrees Centigrade) are eliminated, which have no effects on the reliability, and the mathematical relation between the cutting force, the number of tool changes, and the reliability is finally established. When the cutting force and the number of tool changes increase, the reliability of NC machine tools increases. For further comparison, the authors used a traditional method to evaluate the reliability of this batch of NC machine tools. The result of the case study indicates that, compared with the traditional method, the new method can establish the mathematical relation between the working conditions and the reliability, which makes up the defects of traditional methods and provides a more accurate basis for further reliability improvement design and reliability growth.

\section{Appendix}

\section{A. Failure Records}

Firm:.

Failure time:

Serial Number:.

Machine Tool Type:. .........

Machine Tool Name:

Failure Time

Failure Start Time (hour):...........

Failure End Time (hour):

Repair Time

Repair Start Time (hour)

Repair End Time (hour):...........

Staff Waiting Time (hour):..........

Spare Workpieces Waiting Time

(hour):............

Pictures of failure

Failure phenomenon:..........

Failure position:...........

Failure cause:...........

Pictures of Repair

Failure Tracing:. ..........

Failure Handling:........... .

Replaced Part Name:...........

Specifications and Models:...........

Quantity:

Whether it is an coherent failure:

\section{B. Load Records}

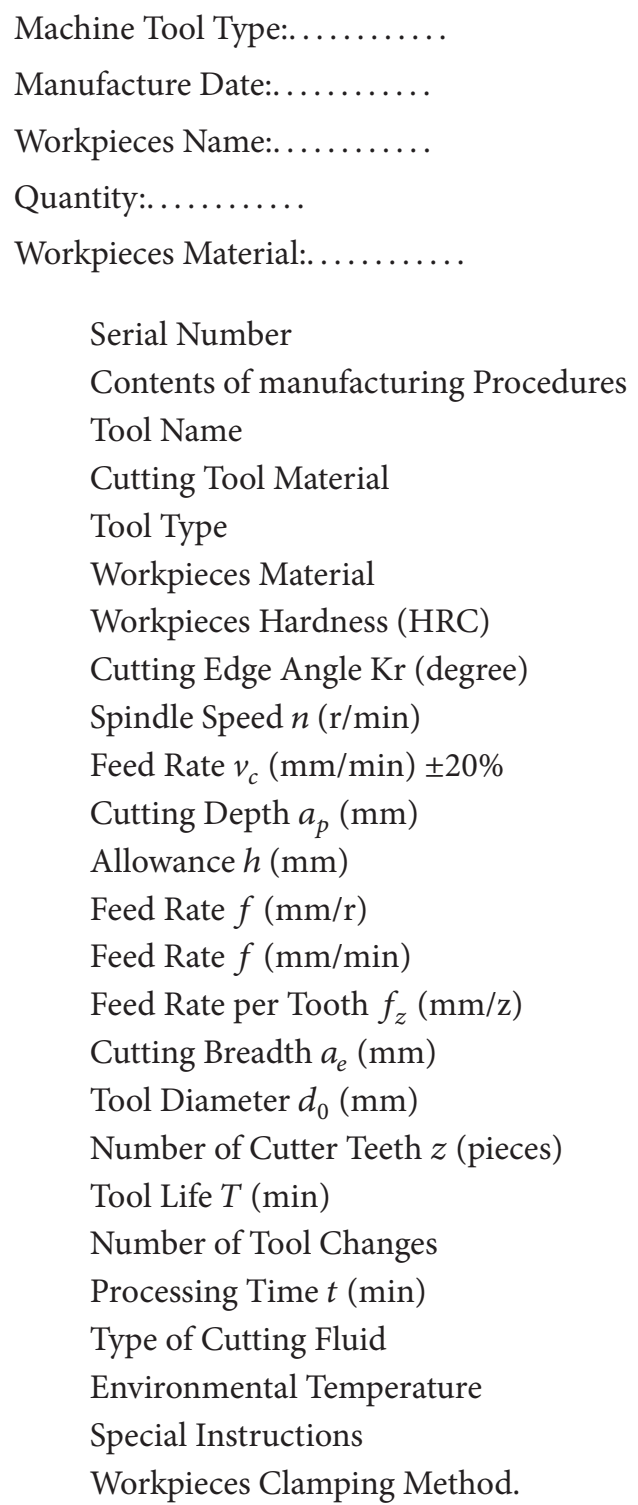

\section{Competing Interests}

The authors declare that there is no conflict of interests regarding the publication of this paper.

\section{Acknowledgments}

Research in this paper was supported by National Science and Technology Major Project of China (Grant no. 2013ZX04011012) of reliability promotion of thousands of Chinese CNC machining centers and the National Natural Science Foundation of China (Grant no. 51505186).

\section{References}

[1] H. Xiao-cong, "Recent development in reliability analysis of NC machine tools," The International Journal of Advanced Manufacturing Technology, vol. 9, pp. 1-17, 2015. 
[2] W. Wang and D. B. Kececioglu, "Fitting the Weibull loglinear model to accelerated life-test data," IEEE Transactions on Reliability, vol. 49, no. 2, pp. 217-223, 2000.

[3] D. Dimitrov, V. Karachorova, and T. Szecsi, "Accuracy and reliability control of machining operations on machining centres," Key Engineering Materials, vol. 615, pp. 32-38, 2014.

[4] G. Hu, Enhancement Coefficient of Motor Vehicle Reliability Enhancement Test, Zhejiang University, 2003.

[5] Y.-J. Chen, R. Zhen, and W.-Y. Huang, "Model and analysis of power system reliability evaluation considering weather change," Automation of Electric Power Systems, vol. 28, no. 21, pp. 17-21, 2004.

[6] L. Wang, S. Zhao, and M. Zhang, "Reliability evaluation of transmission system considering weather change," Power System Technology, vol. 35, no. 7, pp. 66-70, 2011.

[7] Q.-N. Qin, X.-Y. Wei, Z.-W. Huang, and Y. Meng, "Reliability evaluation method of electronic system under variable environments and working conditions," Journal of Central South University: Science and Technology, vol. 44, no. 8, pp. 3254-3260, 2013.

[8] W.-H. Chen, H.-S. Li, W.-Z. Lian, J. Pan, and X.-B. Lu, "Accelerated life test and statistical analysis of aerospace electrical connectors under multiple environmental stresses," Journal of Zhejiang University, vol. 40, no. 2, pp. 348-351, 2006.

[9] L.-N. Ren, Z.-Y. Rui, J. Liu, and C.-L. Lei, "Whole lifecycle reliability assessment of multiple NC machine tools with minimal repair," Journal of Shanghai Jiao Tong University, vol. 49, no. 1, pp. 19-23, 2015.

[10] X.-Z. Zhou, Research on reliability assessment based on Bayesian methods [M.S. thesis], Huazhong University of Science and Technology, Wuhan, China, 2007.

[11] J.-Y. Li, J.-X. Wang, G.-W. Zhou, W. Pu, and Z.-H. Wang, "Accelerated life testing of harmonic driver in space lubrication," Proceedings of the Institution of Mechanical Engineers J: Journal of Engineering Tribology, vol. 229, no. 12, pp. 1491-1502, 2015.

[12] E. Nogueira, M. Vazquez, and J. Mateos, "Accelerated life test of high luminosity AlGaInP LEDs," Microelectronics Reliability, vol. 52, no. 9-10, pp. 1853-1858, 2012.

[13] Z. Yang, C. Chen, F. Chen, and G. Li, "Progress in the research of reliability technology of machine tools," Journal of Mechanical Engineering, vol. 49, no. 20, pp. 130-139, 2013.

[14] B. K. Lad and M. S. Kulkarn, "Reliability and maintenance based design of machine tools," International Journal of Performability Engineering, vol. 9, no. 3, pp. 321-332, 2013.

[15] Y. Zhang, R. Zheng, G. Shen, and B. Chen, "Reliability analysis for CNC machine tool based on failure interaction," Communications in Computer and Information Science, vol. 134, no. 1, pp. 489-496, 2011.

[16] M. K. Loganathan and O. P. Gandhi, "Reliability evaluation and analysis of CNC cam shaft grinding machine," Journal of Engineering, Design and Technology, vol. 13, no. 1, pp. 37-73, 2015.

[17] J. R. W. Merrick, R. Soyer, and T. A. Mazzuchi, "A Bayesian semiparametric analysis of the reliability and maintenance of machine tools," Technometrics, vol. 45, no. 1, pp. 58-69, 2003.

[18] H.-T. Guo and X.-H. Yang, "Automatic creation of Markov models for reliability assessment of safety instrumented systems," Reliability Engineering and System Safety, vol. 93, no. 6, pp. 829837, 2008.
[19] V. Kumar and K. K. Aggarwal, "Petri Net modelling and reliability evaluation of distributed processing systems," Reliability Engineering and System Safety, vol. 41, no. 2, pp. 167-176, 1993.

[20] M. Marseguerra and E. Zio, Basics of the Monte Carlo Method with Application to System Reliability, LiLoLe Press, Hagen, Germany, 2002.

[21] Z.-J. Yang, Y.-N. Kan, F. Chen, B. Xu, C. Chen, and C. Yang, "Bayesian reliability modeling and assessment solution for NC machine tools under small-sample data," Chinese Journal of Mechanical Engineering, vol. 28, no. 6, pp. 1229-1239, 2015.

[22] O. Haillant, D. Dumbleton, and A. Zielnik, "An Arrhenius approach to estimating organic photovoltaic module weathering acceleration factors," Solar Energy Materials and Solar Cells, vol. 95, no. 7, pp. 1889-1895, 2011.

[23] A. Azrulhisham Engku, W. Mohamad, and W. Mansor, "Inverse power law model for operative life estimation of carbon steel stub axle," SAE Technical Papers 2013-01-0328, 2013.

[24] W. B. Nelson, "Accelerated life testing-step-stress models and data analysis," IEEE Transactions on Reliability, vol. 29, no. 2, pp. 103-108, 1980.

[25] H. Ma and W. Q. Meeker, "Strategy for planning accelerated life tests with small sample sizes," IEEE Transactions on Reliability, vol. 59, no. 4, pp. 610-619, 2010.

[26] N. Kazumitsu, L. Masako, and I. Aya, "An analysis of the length of hospital stay for cataract patients in Japan using discretetype proportional hazard," Mathematics and Computers in Simulation, vol. 79, no. 9, pp. 2889-2896, 2009.

[27] P. J. G. Lisboa, H. Wong, A. Vellido, S. P. J. Kirby, P. Harris, and R. Swindeil, "Survival of breast cancer patients following surgery: a detailed assessment of the multi-layer perceptron and Cox's proportional hazard model," in Proceedings of the IEEE World Congress on Computational Intelligence. The IEEE International Joint Conference on Neural Networks, vol. 1, pp. 112-116, Anchorage, Alaska, USA, May 1998.

[28] D. R. Cox, "Regression models and life-tables," Journal of the Royal Statistical Society. Series B. Methodological, vol. 34, no. 2, pp. 187-220, 1972.

[29] J. Yazhou, S. Guixiang, J. Zhixin, and W. Yiqiang, "Equivalent fatigue load in machine-tool probabilistic reliability. Part II: calculation methodology and practical applications," International Journal of Fatigue, vol. 15, no. 6, pp. 478-487, 1993.

[30] B. K. Lad and M. S. Kulkarni, "A mechanism for linking user's operational requirements with reliability and maintenance schedule for machine tool," International Journal of Reliability and Safety, vol. 4, no. 4, pp. 343-358, 2010.

[31] D. R. Cox, "Partial likelihood," Biometrika, vol. 62, no. 2, pp. 269-276, 1975.

[32] S. Janković and B. Ivanović, "Application of combined NewtonRaphson method to large load flow models," Electric Power Systems Research, vol. 127, pp. 134-140, 2015.

[33] M. Anisimova and O. Gascuel, "Approximate likelihood-ratio test for branches: a fast, accurate, and powerful alternative," Systematic Biology, vol. 55, no. 4, pp. 539-552, 2006.

[34] A. Xing and X. Shi-gang, Concise Manual of Cutting Parameters, China Machine Press, 2011.

[35] Y. Dai, Y.-F. Zhou, and Y.-Z. Jia, "Distribution of time between failures of machining center based on type I censored data," Reliability Engineering and System Safety, vol. 79, no. 3, pp. 377379, 2003. 


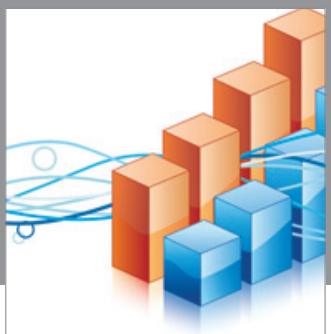

Advances in

Operations Research

vatem alat4

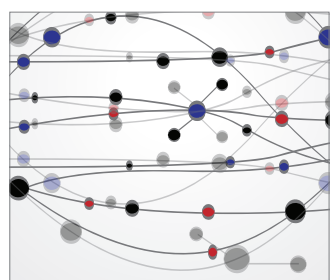

\section{The Scientific} World Journal
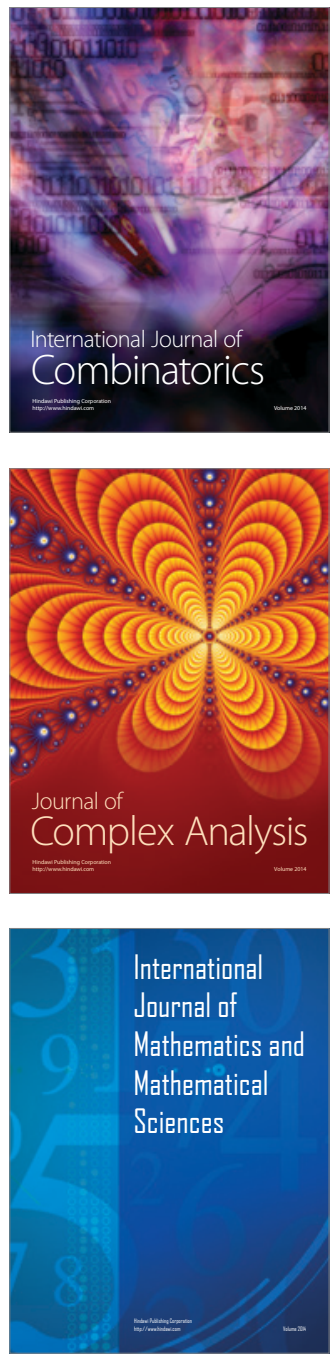
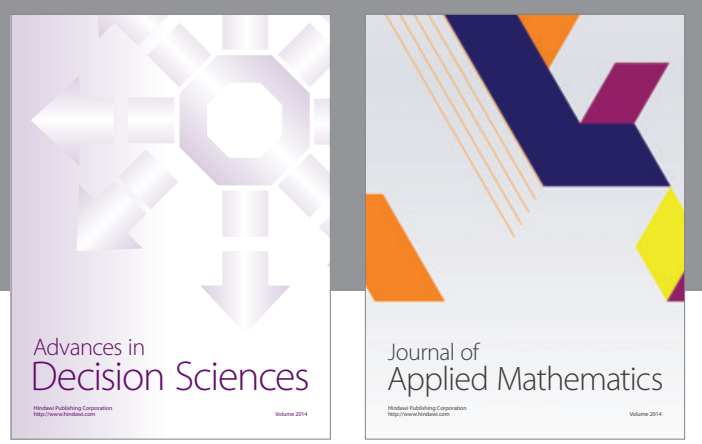

Algebra

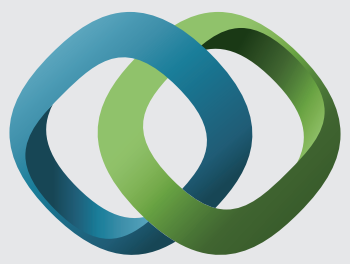

\section{Hindawi}

Submit your manuscripts at

http://www.hindawi.com
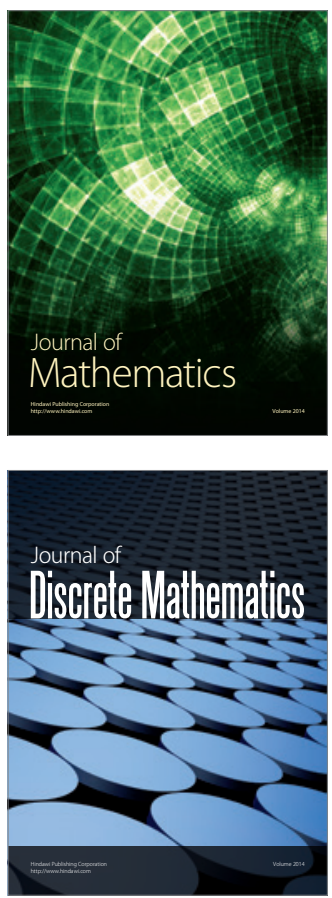

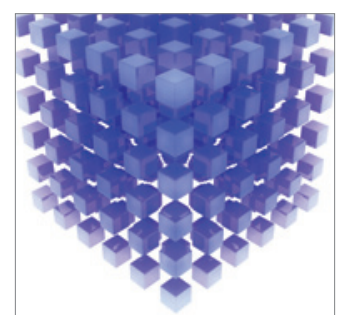

Mathematical Problems in Engineering
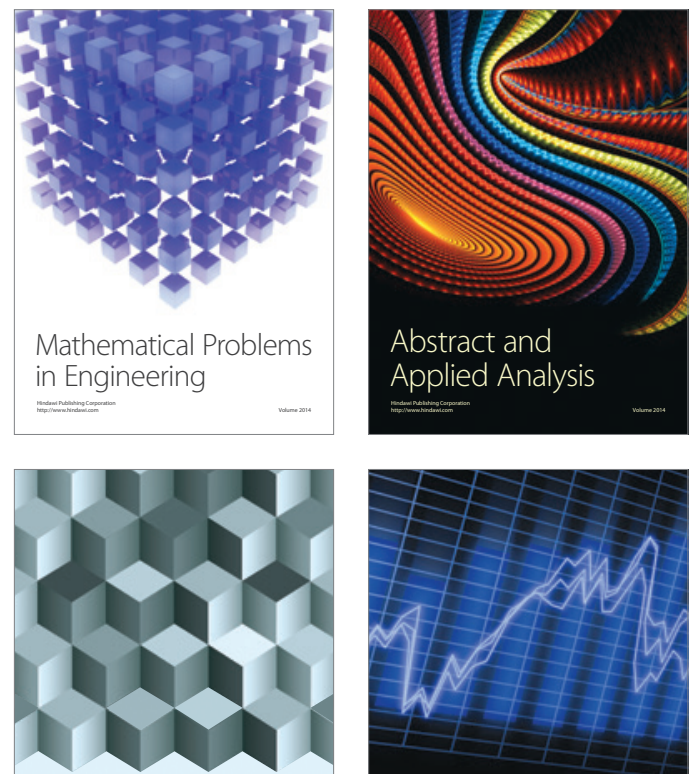

Journal of

Function Spaces

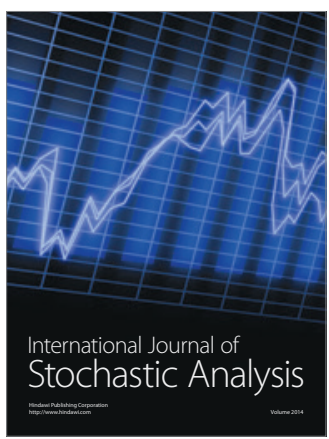

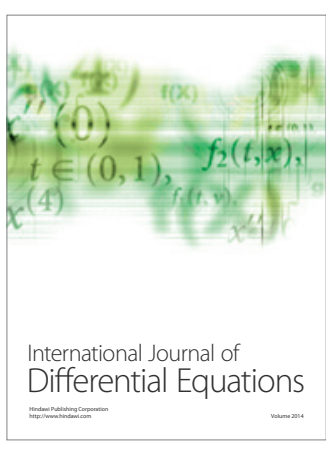
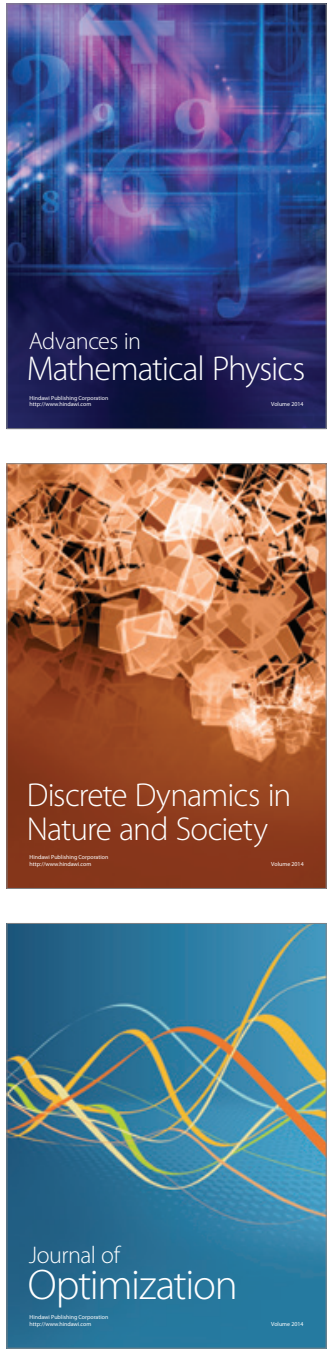